\title{
FINE NEEDLE ASPIRATION CYTOLOGY (FNAC) IN EVALUATION OF NECK MASSES
}

\author{
Mohit Srivastava ${ }^{1}$, Sushant Tyagi², Aksharaditya Shukla ${ }^{3}$
}

${ }^{1}$ Assistant Professor, Department of ENT, Saraswathi Institute of Medical Sciences, Hapur. ${ }^{2}$ Senior Resident, Department of ENT, Saraswathi Institute of Medical Sciences, Hapur. 3Junior Resident, Department of Pathology, MGMMC, Indore.

\begin{abstract}
BACKGROUND: Fine needle aspiration cytology (FNAC) plays an important and determinant role in investigation of neck masses, however inadequate sample yield in FNAC still remains an issue in certain cases. The aim of this study is to evaluate the efficiency and effectiveness of FNAC in investigating neck masses at a tertiary care institute.

METHODS: This is a study of 86 cases with FNAC performed from February 2012 till august 2014 at Department of ENT, SIMS, Hapur. The result were compared with results of 86 patients with neck masses and who underwent excision/incision biopsy for definitive diagnosis of the neck masses.

RESULTS: Out of 86 patients with FNAC 82 patients had a conclusive result (95.34 \%diagnostic yield). Inflammatory lesions (58.5\%) are the common pathology followed by benign lesions (26.8\%) and malignant lesions (14.7\%). 4.65\% had inconclusive results on FNAC due to inadequate sample and dry taps. Excision and incision biopsy had $100 \%$ tissue diagnostic yield with $32.5 \%$ were reactive lymphadenopathy followed by tubercular lymphadenitis which were 20.9\%, $18.6 \%$ were metastatic cancer, $13.9 \%$ were thyroid lesions of which goiter was the most common, $9.3 \%$ were cystic swellings and $4.7 \%$ were salivary gland lesions including sialadenitis. In this study overall accuracy rate of FNAC was $94.06 \%$ with sensitivity of $88.64 \%$, specificity of $94.82 \%$, and positive predictive value of $92 \%$ and negative predictive value of $90.92 \%$.

CONCLUSION: It was concluded that nonspecific reactive lymphadenopathy and tuberculous lymphadenitis are still the most common condition in patients presenting with neck swellings in our region, followed by malignant neoplasms especially metastatic squamous cell carcinoma. FNAC is an easy and suitable investigation tool for the primary assessment of patients with neck swellings on OPD basis. Its diagnostic accuracy is variable and depends on multiple factors as compared to excision/incision tissue biopsy but still it is a good primary investigation for both screening and follow-up of patients to assess the response to treatment.
\end{abstract}

KEYWORDS: Fine Needle Aspiration Cytology (FNAC), Neck Swellings, Tissue Biopsy.

HOW TO CITE THIS ARTICLE: Mohit Srivastava, Sushant Tyagi, Aksharaditya Shukla. "Fine Needle Aspiration Cytology (FNAC) in Evaluation of Neck Masses". Journal of Evolution of Medical and Dental Sciences 2015; Vol. 4, Issue 90, November 09; Page: 15552-15554, DOI: 10.14260/jemds/2015/2230.

INTRODUCTION: A neck mass is the most common clinical neck problem encountered by an ENT surgeon. Neck masses can be classified in relation to the triangles of the neck. The anatomical knowledge of these neck triangles is important for understanding the differential diagnosis of various pathologies presenting as neck swellings. The common pathologies encountered in the neck presenting as a lump are lymphadenopathies (Specific and non-specific, acute and chronic), metastatic carcinoma, lymphoma, thyroid swellings (Goitre, nodules and cysts) and salivary gland swellings (Sialadenitis, cysts, adenomas and carcinomas). The less common pathologies presenting as swelling in the neck are carotid body tumour, bronchial cyst, thyroglossal cyst, cystic hygroma, pharyngeal pouch and lumps of skin appendages. ${ }^{[1]}$

FNAC allows the proper assessment of the cells aspirated from the swellings. However its limitation lies in the fact that it does not allow evaluation of the morphology of the lesion.

Financial or Other, Competing Interest: None.

Submission 15-10-2015, Peer Review 16-10-2015,

Acceptance 26-10-2015, Published 09-11-2015.

Corresponding Author:

Dr. Mohit Srivastava,

Address: Ho. No. 1153, $2^{\text {nd }}$ Floor, Mohan Meakins Society,

Sector 5, Vasundhara, Ghaziabad-201012.

E-mail: dr.mohit141180@gmail.com

DOI:10.14260/jemds/2015/2230.
False-negative and false-positive results are known to occur in FNAC due to which a definitive diagnosis is necessary for cases with clinical suspision.

Still FNAC is a simple investigation tool and is associated with minimal patient trauma and complication rate. The results of FNAC are rapidly available as compared to biopsy, moreover the cost of the procedure is considerably lower. Hence FNAC still remains a valuable diagnostic tool and is a recommended first line investigations of most of the neck swellings. The purpose of our study was to highlight ratio of various neck pathologies in our region with the help of FNAC in outpatient clinic.

MATERIAL AND METHODS: This study was conducted from February 2012 till august 2014 at Department of ENT, SIMS, Hapur. A total of 86 cases were selected. Fine Needle Aspiration Cytology was done in all the 86 cases. Slides were made immediately and sent to the department of pathology for evaluation of cytology. In few cases, patients were sent to the cytologist for second sample due to error in sample collection. Any patients with mass other than neck masses were excluded from the study. Apparatus used included $10 \mathrm{ml}$ or $20 \mathrm{ml}$ disposable plastic syringe, 22-25 gauge. The data analysis was performed using SPSS version 10.

RESULTS: The study included 86 patients with neck swellings. There were $52(60.46 \%)$ female and $34(39.53 \%)$ male patients with an age range of $12-68$ years. 
Out of 86 patients with FNAC 82 patients had a conclusive result (95.34\% diagnostic yield).

Inflammatory lesions $(58.5 \%)$ are the most common pathology followed by benign lesions $(26.8 \%)$ and malignant lesions $(14.7 \%$ ). $4.65 \%$ had inconclusive results on FNAC due to inadequate sample and dry taps.

Excision and incision biopsy had $100 \%$ tissue diagnostic yield with $32.5 \%$ were reactive lymphadenopathy followed by tubercular lymphadenitis which were $20.9 \%$, $18.6 \%$ were metastatic cancer, $13.9 \%$ were thyroid lesions of which goiter was the most common, $9.3 \%$ were cystic swellings and $4.7 \%$ were salivary gland lesions including sialadenitis.

DISCUSSION: Head and neck masses often pose a challenging diagnostic problem to the clinician. Malignancy remains an important differential diagnosis and neck mass is often the first or the only symptom of this disease. Although surgical biopsy is the commonest method of tissue diagnosis, FNAC is in practice since the 1930s. This method has become popular as a diagnostic step in the evaluation of a head and neck mass.[2]

In our study Reactive lymphadenitis were seen in $32.5 \%$ of the cases. Reactive lymphadenopathy may occur as part of specific disease or purely as non-specific response. Results were comparable to the study done by Ahmad et al.[3]

Tubercular/granulomatous lymphadenitis was found in 20.9 \%cases in our study, which was comparable to the study carried out by Manjula K et al.[4] El Hag, et al.[5] carried out a similar study in Saudi Arabia over a period of 5 years which included 225 patients which showed reactive/nonspecific lymphadenitis to be the commonest cause of neck masses accounting for $33 \%$ of cases. Tuberculous lymphadenitis was found to be the next most common pathology constituting $21 \%$ of cases followed by malignant swellings found in $13 \%$ of cases.

Different studies have shown the importance of the quality of cytological preparation besides the representativeness of the aspirate especially in the diagnosis of reactive lymphadenitis and in the diagnosis and classification of Lymphomas.[6]

The rising incidence of cutaneous SCC worldwide makes it increasingly likely that clinicians may also encounter regional nodal metastases of this type of skin cancer in the parotid gland and the upper levels of the neck. Therefore, high risk areas such as ear and scalp should also be examined thoroughly. If neck nodes are found in levels Va and $\mathrm{Vb}$, examination of the skin of the neck and torso should be performed as well. Although rare, Merkel cell carcinoma is another cutaneous aggressive malignancy of which half of the cases presents primarily in the head and neck with a high propensity for neck node metastases.[7]

FNAC is a safer choice for initial evaluation of masses suspicious of malignancy as the frequency of needle seeding of tumor cells in the procedure is reported as low as 0.003$0.009 \% .{ }^{[8]}$ Hence, considering this range, tumor risk in FNAC is almost nonexistent in comparison to excision biopsy.

To avoid or minimize false positive results various factors including regenerative changes, metaplasia and others should be taken into considerations while reporting.
False negative results may be due to cystic change, necrotic and hemorrhagic areas revealing no diagnostic cellular yield. [9] With increasing cost of medical facilities, any technique which speeds up the process of diagnosis, limits the physical and psychological trauma to the patient, and saves the expenditure of hospitalization, will be of tremendous value. It may also help the surgeon to select, guide, and modify surgical planning in patients requiring surgery. ${ }^{[10]}$

CONCLUSION: It was concluded that nonspecific reactive lymphadenopathy and tuberculous lymphadenitis are still the most common condition in patients presenting with neck swellings in our region, followed by malignant neoplasms especially metastatic squamous cell carcinoma. FNAC is an easy and suitable investigation tool for the primary assessment of patients with neck swellings on OPD basis. Its diagnostic accuracy is variable and depends on multiple factors as compared to excision/incision tissue biopsy but still it is a good primary investigation for both screening and follow-up of patients to assess the response to treatment.

\section{REFERENCES:}

1. Lumley JSP. Physical signs. 18th ed. Oxford: Butterworth Heinemann; 1997.

2. Raju G, Kakar PK, Das DK, Dhingra PL, Bhambhani S. Role of fine needle aspiration biopsy in head and neck tumours. The J of laryngol and Otol 1988; 102:248-51.

3. Ahmad T, Naeem M, Ahmad S, Samad A, Nasir A. fine needle aspiration cytology and neck swellings in the surgical outpatient. J Ayub Coll Abbottabad 2008; 20:3032.

4. Amrikachi M, Ramzy I, Rubenfeld S, WheelerTM. Accuracy of Fine NeedleAspiration of Thyroid. Arch Pathol Lab Med 2001; 125:484-488.

5. El Hag IA, Chiedozi LC, al Reyees FA, Kollur SM. Fine needle aspiration cytology of head and neck masses. Seven years' experience in a secondary care hospital. Acta Cytol 2003; 47:387 92

6. Tilak V, Dhaded AV, Jain R. Fine needle aspiration cytology of head and neck masses. Indian J Pathol Microbiol. 2002; 45(1): 23-9.

7. J. M. Balm, M. L. F. van Velthuysen, F. J. P. Hoebers, W. V. Vogel, and M. W. M. van den Brekel, "Diagnosis and Treatment of a Neck Node Swelling Suspicious for a Malignancy: An Algorithmic Approach," International Journal of Surgical Oncology, vol. 2010, Article ID 581540, 8 pages, 2010 doi:10.1155/2010/581540.

8. Mohamed MH, Hitam S, Brito-Mutunayagam S, Yunus MRM. Role of FNAC in evaluation of neck masses. J Curr Surg. 2013; 3(1):19-23.

9. Suryawanshi Kishor H.et.al. Spectrum of fnac in palpable head and neck lesions in a tertiary care hospital in india- a 3 years study; Indian Journal of Pathology and Oncology, January - March 2015; 2(1); 7-13.

10. Rathod GB, Parmar P. Fine needle aspiration cytology of swellings of head and neck region. Indian J Med Sci [serial online] 2012 [cited 2015 Oct 12]; 66:49-54. Available from:

http://www.indianjmedsci.org/text.asp?2012/66/3/49/1 10896 


\begin{tabular}{|c|c|c|}
\hline SITE & NO. OF CASES & PERCENTAGE \% \\
\hline Lymphnode & 62 & 72.09 \\
\hline Thyroid gland & 14 & 16.27 \\
\hline Salivary gland & 6 & 6.97 \\
\hline Misc. & 4 & 4.65 \\
\hline \multicolumn{2}{|c}{ Table 1 } \\
\hline
\end{tabular}

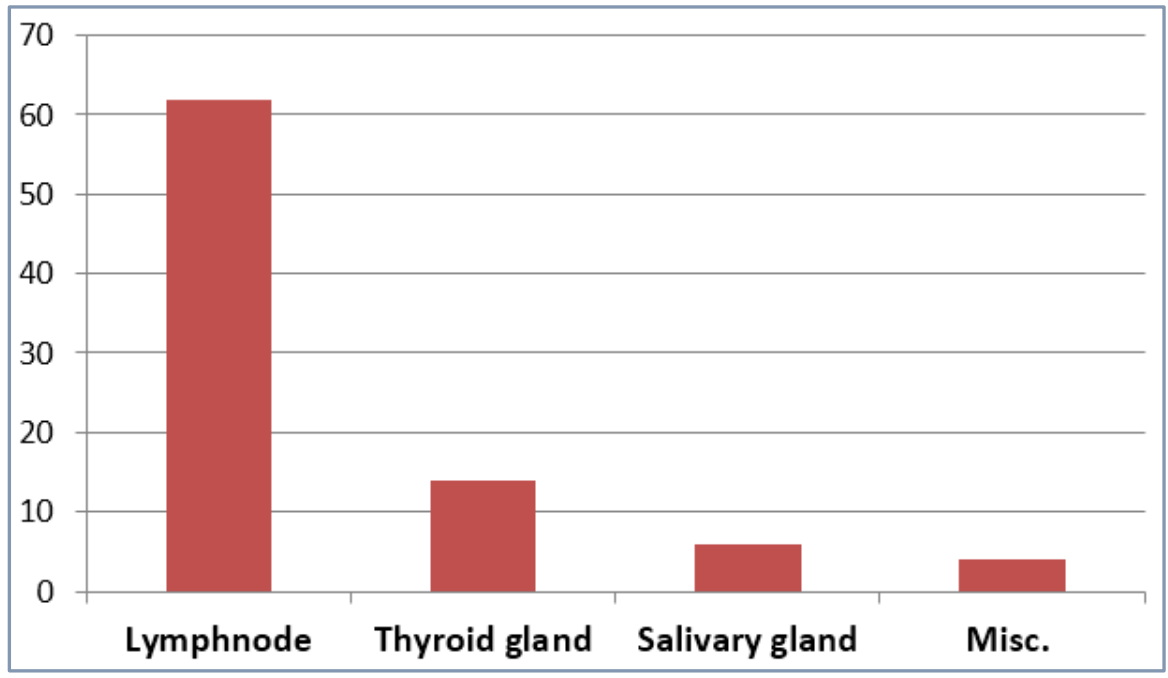

Fig. 1

\begin{tabular}{|c|c|c|c|}
\hline Sl. NO & NECK LESIONS & NO. OF CASES & PERCENTAGE \% \\
\hline 1 & Reactive Lymphadenitis & 28 & 32.5 \\
\hline 2 & Tubercular Lymphadenitis & 18 & 20.9 \\
\hline 3 & Goiter & 12 & 13.9 \\
\hline 4 & Metastasis & 16 & 18.6 \\
\hline 5 & Sialadenitis & 4 & 4.7 \\
\hline 6 & Cystic lesion & 8 & 9.3 \\
\hline \multicolumn{3}{|c|}{ Table 2 } \\
\hline
\end{tabular}

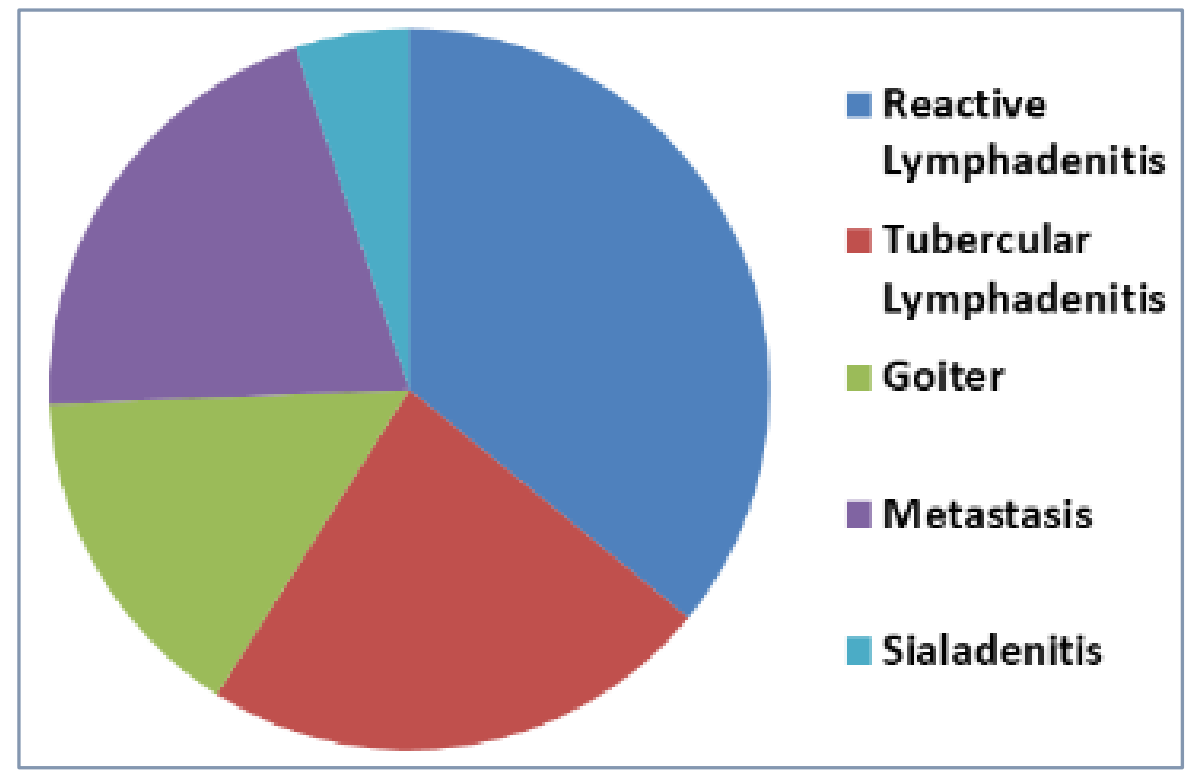

Fig.2

In this study overall accuracy rate of FNAC was $94.06 \%$ with sensitivity of $88.64 \%$, specificity of $94.82 \%$, and positive predictive value of $92 \%$ and negative predictive value of $90.92 \%$. 